\title{
LAS FAUNAS DE MAMÍFEROS DEL EOCENO DE LA CUENCA DEL DUERO (CASTILLA Y LEÓN, ESPAÑA). SÍNTESIS BIOESTRATIGRÁFICA Y BIOGEOGRÁFICA
}

\author{
Miguel Angel CUESTA RUIZ-COLMENARES
}

Dpto. de Geología, Facultad de Ciencias, Universidad de Salamanca, 37008 Salamanca y Avda. General Goded, $37\left(3^{\circ} \mathrm{B}\right), 34005$ Palencia.

Cuesta Ruiz-Colmenares, M.A. 1999. Las faunas de mamíferos del Eoceno de la Cuenca del Duero (Castilla y León, España). Síntesis bioestratigráfica y biogeográfica. [Eocene mammal faunas from the Duero Basin (Castilla y León, Spain). A biostratigraphic and biogeographic synthesis.] Revista Española de Paleontología, 14(2), 203-216. ISSN 0213-6937.

\begin{abstract}
A synthesis of the Eocene continental mammal faunas from the Duero Basin is given. At present 14 mammal localities are known, containing Marsupialia, Lipotyphla, Anagalida, Proteutheria, Creodonta, Primates, Rodentia, Artiodactyla and Perissodactyla. Based on revised faunal lists, and especially on the perissodactyls and rodents, four groups of localities can be recognised ranging from the middle of the mid Eocene (MP 13-14) to the end of the late Eocene.

The Perissodactyla and Rodentia from the upper part of the middle Eocene (MP 15-16) are the best known mammals. They show individuality with regard to the faunas from western Europe, since the genera Paranchiplophus, Franzenium, Cantabrotherium and Pairomys, and also several species are either restricted to the Duero Basin, or are only known from areas of the western Iberian Peninsula outside the Duero Basin. The presence of these endemic taxa clearly suggest that during that period a western Iberian region existed whose mammal fauna was different from that of western Europe. A generally very hypsodont dental pattern in the Perissodactyla and Rodentia seems to indicate an open and dry country. Maybe this factor was combined with geographical isolation.
\end{abstract}

Keywords: Mammals, Middle Eocene, Upper Eocene, biogeography, Duero Bassin, Castilla y León, Spain.

\section{RESUMEN}

En este trabajo se realiza una síntesis de los mamíferos del Eoceno continental de la Cuenca del Duero. Se conocen actualmente 14 yacimientos con mamíferos, que incluyen Marsupiales, Lipotiflos, Anagálidos, Proteuterios, Creodontos, Primates, Roedores, Artiodáctilos y Perisodáctilos. Las listas faunísticas han sido actualizadas. A partir de tales faunas, y especialmente de los Perisodáctilos y los Roedores, se pueden reconocer cuatro grupos de yacimientos, comprendidos entre la parte media del Eoceno medio (MP 13-14) y el final del Eoceno superior.

Los Perisodáctilos y Roedores de la parte superior del Eoceno medio (MP 15-16) son los grupos mejor conocidos y muestran una clara individualidad respecto a los de Europa occidental, ya que los géneros Paranchilophus, Franzenium, Cantabrotherium y Pairomys, y varias especies o son exclusivos de la Cuenca del Duero o sólo se conocen fuera de ella en ciertas áreas occidentales de la Península Ibérica. La presencia de estos taxones endémicos sugiere la existencia de una región ibérica occidental faunísticamente diferenciada del resto de Europa occidental durante la mencionada época. La generalización de un patrón dentario marcadamente hipsodonto en los citados Perisodáctilos y Roedores, parece corresponder a la existencia de unos medios abiertos y secos durante la parte superior del Eoceno medio. Este factor quizás pudo haberse combinado con algún proceso de aislamiento geográfico.

Palabras clave: Mamíferos, Eoceno medio, Eoceno superior, biogeografía, Cuenca del Duero, Castilla y León, España. 


\section{INTRODUCCIÓN}

En la Cuenca del Duero (Castilla y León, España) los terrenos atribuidos al Paleógeno continental se distribuyen en una serie de afloramientos independientes entre sí, situados en los bordes de la cuenca (Fig. 1; Portero et al., 1982; Colmenero et al., 1982; Jiménez, 1983; Jiménez et al., 1983). En dos de ellos, el afloramiento suroccidental (provincias de Salamanca y Zamora) y la subcuenca de Almazán (provincia de Soria), se localizan una serie de yacimientos de vertebrados (Fig.1) que han proporcionado recientemente una serie de faunas de mamíferos de edad eocénica; existe además un único yacimiento oligocénico, el de Los Barros (Valle del Amblés, provincia de Ávila).

El propósito de este trabajo es sintetizar la información existente sobre los mamíferos del Eoceno de la Cuenca del Duero, intentando enfatizar su relevancia en el Eoceno continental ibérico. Los objetivos fundamentales han sido actualizar las listas faunísticas de los distintos yacimientos, sintetizar su posición bioestratigráfica y resumir las implicaciones biogeográficas de tales faunas, buscando dar una visión global de las mismas, en especial de los Perisodáctilos, el grupo mejor documentado y que había sido tratado con anterioridad en varios trabajos independientes.

El afloramiento paleógeno suroccidental forma una banda alargada de dirección aproximada N-S de $100 \mathrm{Km}$ de longitud por $50 \mathrm{Km}$ de anchura. Se han identificado tres tramos, de los que el inferior (Preluteciense según Jiménez, 1970 y 1971), por el momento no fosilífero, se atribuye al Paleoceno. Los tramos medio y superior, por lo general atribuidos al Eoceno, son discordantes sobre el inferior y en ellos se localizan todos los yacimientos de vertebrados paleógenos conocidos hasta la fecha en el mencionado afloramiento. Dichos tramos presentan una gran variedad litológica, habiéndose descrito una serie de formaciones y facies (información geológica, geográfica y bibliográfica en: Alonso-Gavilán, 1981; Portero et al., 1982; Corrochano y Carballeira, 1983; Jiménez, 1983; Jiménez et al., 1983; Gil, 1992). Los yacimientos de mamíferos son, en unos casos, localidades clásicas, conocidas desde finales del siglo XIX o principios del XX (Sanzoles, Corrales y San Morales), mientras que la mayoría se han descubierto en los últimos 20 años. Su distribución geográfica es la siguiente:

+ Provincia de Zamora: El Viso-Sanzoles, Corrales del Vino, Casaseca de Campeán, Jambrina, Santa Clara de Avedillo, Fuentesaúco y Molino del Pico.

+ Provincia de Salamanca: Caenes, San Morales y Babilafuente.

Por otra parte, hay varios yacimientos mencionados en los trabajos que sobre la zona se publicaron en la primera mitad del siglo XX, que no han podido localizarse y de los que además se desconoce el paradero del material fósil correspondiente: Villamayor, Cabrerizos, Aldealengua y Aldearrubia (Salamanca; ver Antecedentes).

La subcuenca de Almazán (provincia de Soria) se sitúa en el borde oriental de la Cuenca del Duero, con los yacimientos de Mazaterón, Miñana y Deza I y II. Este afloramiento paleógeno constituye una franja adosada a la rama occidental de la Cordillera Ibérica, con una potente sucesión en la que se han descrito varias unidades (Guisado et al., 1988; Armenteros et al., 1989; Gil, 1992).

\section{ANTECEDENTES}

La existencia de vertebrados paleógenos en la Cuenca del Duero es conocida desde el siglo pasado; no obstante, durante mucho tiempo su conocimiento fue muy reducido, y restringido al sector suroccidental.

Las primeras noticias de vertebrados paleógenos en la Cuenca del Duero se deben a Vilanova (1873) quien cita restos de Quelonios y Cocodrilos atribuibles al Eoceno procedentes de Sanzoles (Zamora), y Calderón (1902) que señala restos de mamíferos en Villamayor (Salamanca).

Los trabajos posteriores (Miquel, 1906; HernándezPacheco, 1915 y 1943; Roman y Royo, 1922; Roman, 1923; Sáenz, 1934; Crusafont y Truyols, 1957, Jiménez, 1970 y 1971) aportaron escasos datos al conocimiento de los mamíferos paleógenos, si bien permitieron establecer una separación entre el Eoceno medio de Corrales (provincia de Zamora), con Lophiodon isselense Fischer, 1829, y Chasmotherium minimum (Fischer, 1829), y el Eoceno superior de las proximidades de Salamanca (San Morales, Cabrerizos, Aldealengua y Aldearrubia), con "Paloplotherium" minor (Cuvier, 1804) que actualmente se incluye en Plagiolophus, Xiphodon gracile Cuvier, 1822, Suido indeterminado, Palaeotherium magnum Cuvier, 1804, y P. minus Cuvier, 1804; como señala Casanovas (1975), éste último debe nombrarse en realidad como Plagiolophus minor (Cuvier, 1804). En Sanzoles también se cita un Palaeotherium talla curtum Cuvier, 1812. Por desgracia se desconoce actualmente el paradero de la mayor parte de este material y, ante la imposibilidad de realizar una revisión, no se ha tenido en cuenta en las listas faunísticas de este trabajo; para consultar las faunas de todos estos yacimientos ver Gil (1992) y Checa y Casanovas (1990). Los primeros datos sobre Roedores se deben a Garzón y López-Martínez (1978) y López-Martínez (1984).

El conocimiento paleontológico de la subcuenca de Almazán (Soria) se inicia en una época mucho más reciente que el de la zona suroccidental (Cuesta, 1988; Jiménez et al., 1989; Peláez-Campomanes et al., 1989).

En los últimos 20 años se ha avanzado considerablemente en el conocimiento, en la Cuenca del Duero, de los vertebrados paleógenos en general y de los mamíferos en particular. Las campañas de excavación llevadas a cabo tanto en localidades clásicas como en las descubiertas más recientemente, han supuesto un considerable incremento del material fosilífero disponible, no sólo de mamíferos sino también de reptiles y peces. Paralelamente han aparecido una serie de trabajos, mencionados en el apartado siguiente, que han ampliado considerablemente los conocimientos sobre el Paleógeno en la mencionada cuenca. 


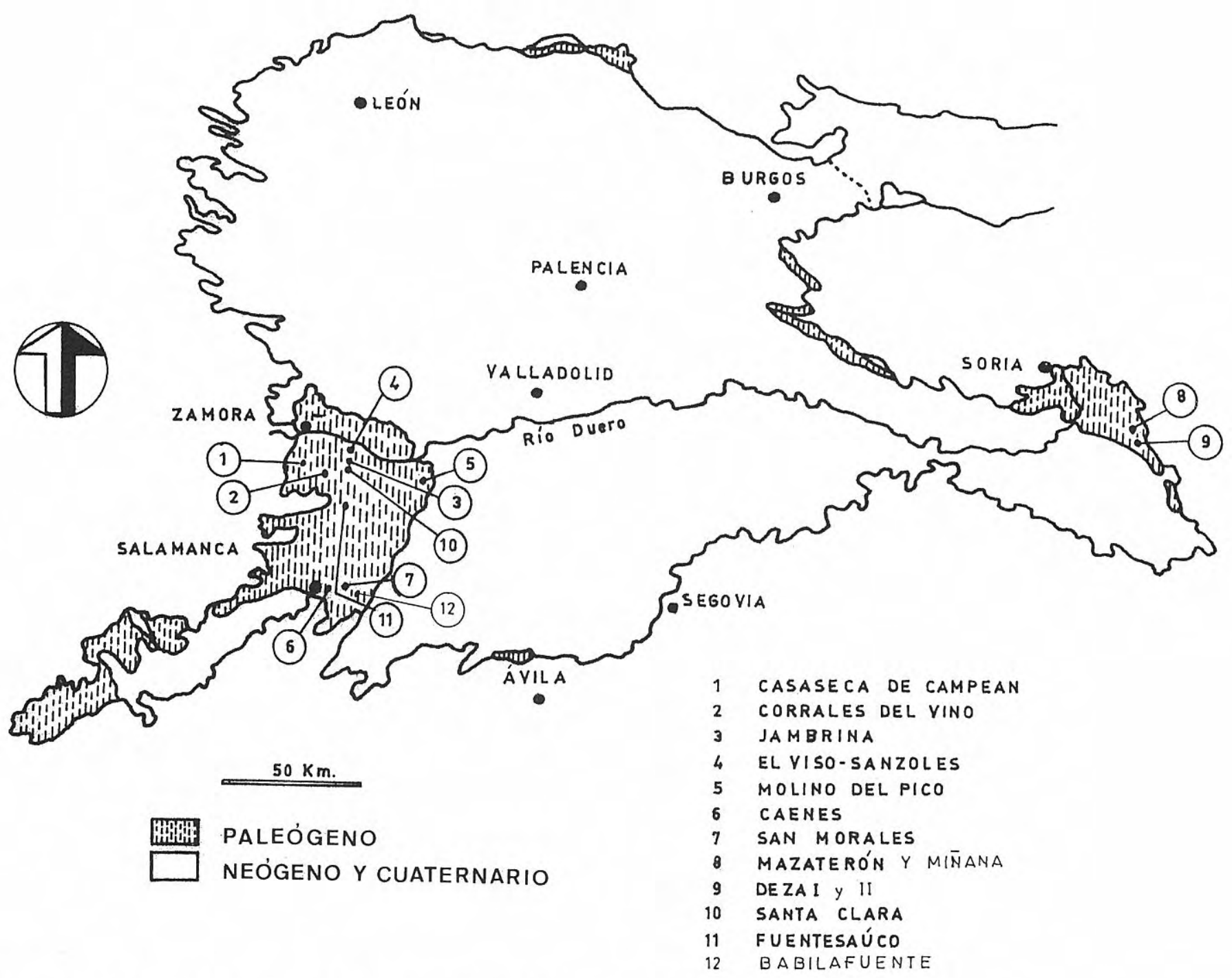

Figura 1. Localización geográfica de los yacimientos de mamíferos del Eoceno de la Cuenca del Duero.

\section{YACIMIENTOS Y FAUNAS}

Se consignan a continuación las listas faunísticas actualizadas de los yacimientos del Eoceno de la Cuenca del Duero que han liberado mamíferos.

El orden mejor documentado y el que más información ha aportado al conocimiento faunístico y biogeográfico de la zona es el de los Perisodáctilos, del que están representados los grupos característicos del Eoceno europeo: Lophiodontidae, Palaeotheriidae y Pachynolophidae, con Pachynolophinae y Plagiolophinae (Cuesta, 1988, 1991, 1992b, 1993a, 1994a, b y c, 1996; Jiménez et al., 1989 y 1994; Cuesta et al., 1993). Para los taxones familiares y subfamiliares de los Perisodáctilos Equoidea se ha adoptado un agrupamiento sistemático recientemente propuesto (Cuesta 1991, 1992b, 1993a, $1994 \mathrm{~b}$ y c). Les siguen en importancia los Roedores, con representantes de Theridomyidae, Pseudosciuridae, Ischyromidae, Gliridae y otros de afinidades inciertas (López-Martínez, 1984; Peláez-Campomanes et al., 1989; Peláez-Campomanes, 1992, 1993 y 1996; Vianey-Liaud et al., 1994; Peláez-Campomanes y López-Martínez,
1996). El resto de órdenes de mamíferos presentes son menos conocidos: Proteuterios, Anagálidos, Lipotiflos, Marsupiales (Peláez-Campomanes et al., 1989), Primates (Peláez-Campomanes et al., 1989; Moyà y Köhler, 1992), Creodontos (Cuesta, 1992a), Artiodáctilos (PeláezCampomanes et al., 1989; Cuesta, 1992c, 1993b, 1997 y 1998). Además se han recopilado datos paleontológicos sobre la fauna de vertebrados del yacimiento de Mazaterón (Cuesta y Jiménez, 1994). El material se encuentra depositado en la "Sala de las Tortugas" de la Universidad de Salamanca, así como en el Museo Nacional de Ciencias Naturales de Madrid y el Departamento de Paleontología de la Universidad Complutense de Madrid.

Listas faunísticas previas han sido aportadas por Checa y Casanovas (1990), Gil (1992), Cuesta y Jiménez (1994) y Antunes et al. (1997). Así mismo, Checa y Casanovas (1990), Antunes et al. (1997) y Morales y Nieto (1997) aportan información sobre los mamíferos del Eoceno de la Cuenca del Duero en el contexto más amplio del Paleógeno ibérico. La posición estratigráfica de los yacimientos de mamíferos se muestra en la figura 2 
y se ha tenido en cuenta la escala biocronológica del Paleógeno continental europeo, propuesta en SchmidtKittler ed. (1987), revalorizada y matizada en el congreso BiochroM'97 (Aguilar et al., 1997).

En todos los yacimientos son muy frecuentes restos fosilíferos de reptiles, fundamentalmente Quelonios y Cocodrilos y en algunos de ellos abundan también los peces (para información sobre estos grupos ver Cuesta, 1993a; De La Peña, 1992; Jiménez, 1992b; Ortega y Buscalioni, 1992).

\section{* Casaseca de Campeán; MP 13-14.}

Artiodactyla indet.

Perissodactyla: Pachynolophus sp.; Plagiolophus casasecaensis Cuesta, 1994; Palaeotheriidae indet.; Lophiodon cf. tapirotherium Desmarest, 1822; Paralophiodon aff. isselense (Fischer, 1829); Lophiodontidae indet.

\section{* Corrales del Vino; MP 13-14.}

Perissodactyla: Pachynolophinae indet.; Pachynolophidae indet.; Paralophiodon aff. isselense; Lophiodontidae?

\section{* EI Viso-Sanzoles; MP 14.}

Rodentia: Zamoramys extraneus Peláez-Campomanes y López-Martínez, 1996.

Perissodactyla: Pachynolophus sp.; Plagiolophus sp.

* Jambrina; MP 13-14.

Lipotyphla: Nyctitheridae indet.

Perissodactyla: Lophiodontidae indet.;

Pachynolophinae indet.

* Santa Clara de Avedillo; MP 13-14.

Marsupialia: Peratherium matronense Crochet, 1979. Proteutheria: cf. Palaeoryctidae indet.

Anagalida: cf. Anagalida indet.

Primates: Anchomomys cf. stehlini Gingerich, 1977.

Rodentia: Zamoramys extraneus; Microparamys sp.

Artiodactyla: cf. Dichobunidae indet.

Perissodactyla: Plagiolophus cf. casasecaensis Cuesta, 1994.

* Caenes; MP 15-16.

Creodonta indet.

Primates: Anchomomys sp., Microadapis sp.

Artiodactyla: Leptotheridium sp.

Perissodactyla: Paranchilophus sp.; Plagiolophus mazateronensis Cuesta, 1994; Franzenium durense Cuesta, 1993; Lophiodontidae indet.

\section{* San Morales; MP 15-16.}

Perissodactyla: Lophiodon sanmoralense Cuesta, 1994; cf. Anchilophus; Plagiolophus sp.; Palaeotheriidae indet.

\section{* Mazaterón; MP 15-16.}

Creodonta: Proviverra sp.

Primates: Anchomomyini indet.; Adapidae indet.;
Pseudoloris sp.

Rodentia: Sciuroides cf. siderolithicus (Pictet y Humbert, 1869); Pseudoltinomys crebrum PeláezCampomanes, 1996; Pairomys ibericus Vianey-Liaud, Schmidt-Kittler y Peláez-Campomanes, 1994.

Artiodactyla: cf. Dacrytherium; cf. Leptotheridium; cf. Dichodon; Anoplotheriinae indet.

Perissodactyla: Paranchilophus remyi Casanovas y Santafé, 1989; Plagiolophus mazateronensis; Plagiolophus sp.; Leptolophus sp.; Palaeotherium giganteum Cuesta, 1993; Cantabrotherium casanovasae Cuesta, 1993; Franzenium durense; Lophiodon sp.

* Miñana; MP 15.

Marsupialia: Amphiperatherium cf. mimutum (Aymard, 1846).

Lipotyphla: Saturninia cf. mamertensis Sigé, 1976.

Rodentia: Sciuroides cf. siderolithicus; Pseudoltinomys crebrum; Pairomys ibericus.

* Deza I; MP 15-16.

Perissodactyla: Plagiolophus sp.

* Fuentesaúco; MP 15-16.

Perissodactyla: Franzenium durense.

* Babilafuente; MP 16.

Rodentia: Remys aff. minimus Hartenberger, 1973.

* Deza II; MP 17.

Rodentia: Theridomys euzetensis (Depéret, 1917); Glamys priscus (Stehlin y Schaub, 1951).

* Molino del Pico; Eoceno superior u Oligoceno inferior?.

Perissodactyla: Palaeotheriidae indet.; Plagiolophus sp.

\section{BIOESTRATIGRAFÍA}

Las dataciones del Paleógeno de la Cuenca del Duero presentan numerosas dificultades, como son los problemas de correlación entre las diferentes áreas, la escasez de dataciones absolutas, el tratarse de faunas pobremente conocidas, así como la existencia de fenómenos de endemismo (ver Jiménez, 1992a para una revisión de las dataciones en la zona).

No obstante, el establecimiento de la posición biocronológica de los yacimientos paleógenos de la Cuenca del Duero con mamíferos (Fig. 2) ha avanzado considerablemente en los últimos años gracias al conocimiento de diferentes grupos de mamíferos, especialmente Perisodáctilos y Roedores.

Basándonos esencialmente en las asociaciones faunísticas de Perisodáctilos (Cuesta, 1991, 1992b, 1993a, b, 1994a, b y c) junto con la información aportada por Roedores (López-Martínez, 1984; Peláez-Campomanes et al., 1989; Peláez-Campomanes, 1992, 1993 y 1996; Vianey-Liaud et al., 1994; Peláez-Campomanes y 
López-Martínez, 1996) y, en menor medida, del resto de órdenes de mamíferos, se pueden diferenciar cuatro grupos de yacimientos de mamíferos. Para ello se ha tenido en cuenta la escala biocronológica en uso para el Paleógeno continental europeo, cuyos niveles de referencia fueron definidos en el simposio de Mainz (Schmidt-Kittler ed., 1987) y recientemente reafirmados y matizados en el congreso BiochroM'97, de Montpellier (Aguilar et al. eds., 1997). También se han aceptado las correlaciones marino-continentales adoptadas en estos trabajos y la separación Eoceno medio-Eoceno superior en el límite Bartoniense-Priaboniense (MP16-MP17), generalizada en los trabajos de BiochroM'97. Como señalan Casanovas y Moyà (1992) la subdivisión del Eoceno continental europeo en Neustriense, Rhenaniense y Headoniense expuesta en el simposio de München de 1975 (Fahlbush, 1976), no es del todo correcta ya que tan sólo el Headoniense tiene un establecimiento formal. Los trabajos sobre Reptiles del Eoceno de la Cuenca del Duero están de acuerdo básicamente con lo expuesto para los mamíferos (Jiménez et al., 1983; Martín et al., 1987).

Los grupos de yacimientos son los reseñados a continuación.

\section{Parte media del Eoceno medio (Luteciense} superior-Bartoniense inferior, MP 13-14)

Yacimientos: Casaseca de Campeán, Corrales del Vino, El Viso-Sanzoles, Jambrina y Santa Clara de Avedillo (Fig. 2).

Las faunas de Perisodáctilos se caracterizan por:

- diversidad de Lophiodontidae: Lophiodon cf. tapirotherium, Paralophiodon aff. isselense, Lophodontidae indet. (afín a Lophiaspis) y Lophiodontidae?.

- presencia de Pachynolophinae primitivos: Pachynolophus sp. y otras formas de más difícil determinación.

- presencia de Plagiolophinae primitivos: Plagiolophus casasecaensis y otros.

- Palaeotheriidae escasos.

Tal asociación de Perisodáctilos es la típica de la parte media del Eoceno medio europeo, tanto del Luteciense superior como del Bartoniense inferior (MP 13-14), como las que aparecen en los yacimientos de Europa Occidental, entre los que destacan Geiseltal, Bouxwiller, algunos yacimientos de la Cuenca de París, Egerkingen e Issel (Rat, 1965; Hartenberger, 1970; Jaeger, 1971; Dedieu, 1976 y 1977a y b; Franzen y Haubold, 1986a y b). En efecto, todas estas asociaciones de Perisodáctilos se caracterizan por la abundancia y diversidad de Lophiodontidae, presencia de Pachynolophinae primitivos, junto con los primeros representantes de Plagiolophinae y Palaeotheriidae.

Una notable diversidad de lofiodóntidos es una constante en todo el Eoceno medio excepto en su parte terminal (MP 16, Robiac) en que su diversidad baja de manera evidente. Los lofiodóntidos Paralophiodon aff. isselense y Lophiodon cf. tapirotherium de Casaseca de Campeán presentan muchas similitudes con $P$. isselense y L. tapirotherium del yacimiento francés de Issel. $P$.

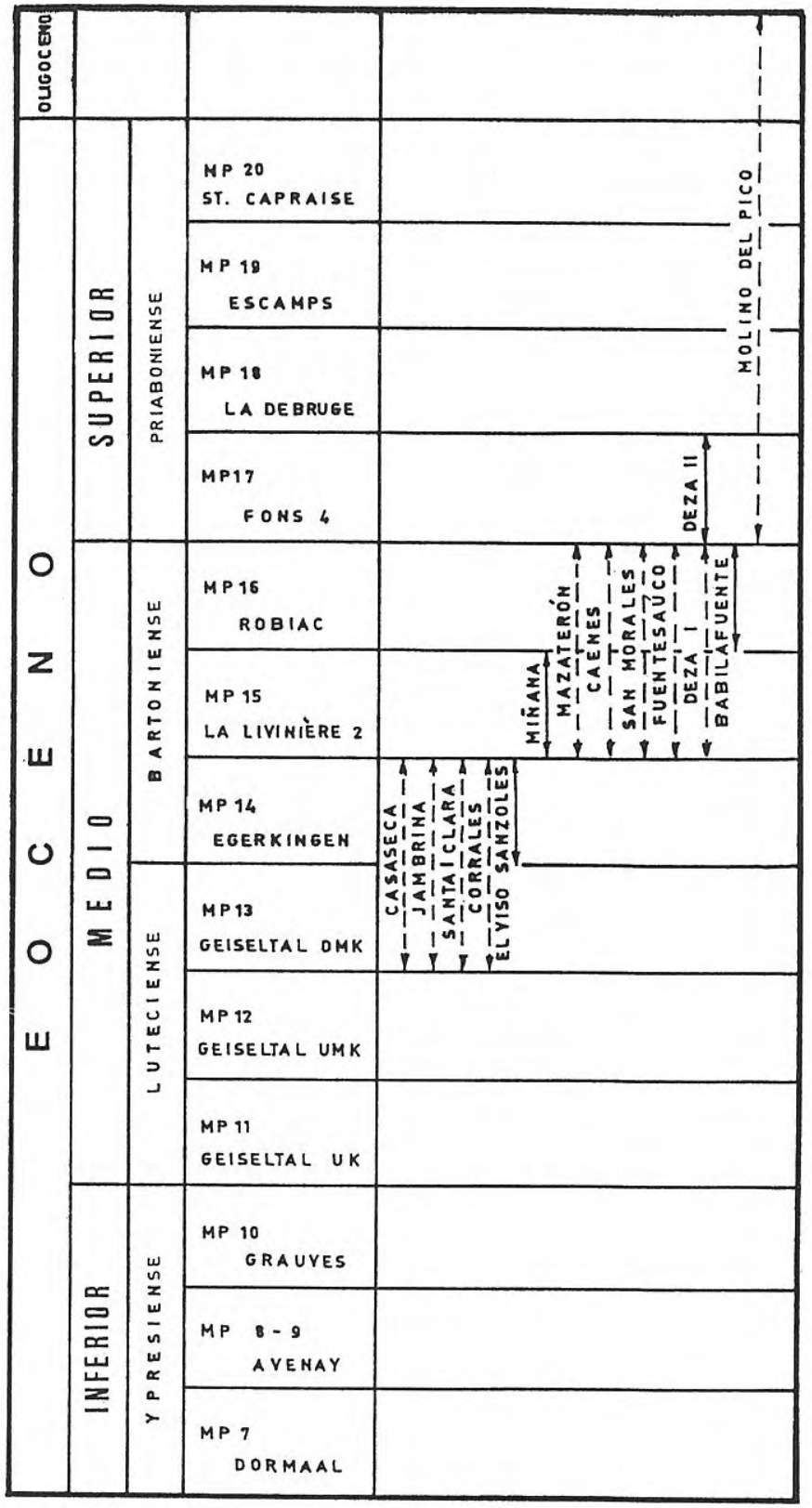

Figura 2. Posición estratigráfica de los yacimientos de mamíferos del Eoceno de la Cuenca del Duero.

isselense está restringido a MP 14 mientras que $L$. tapirotherium se encuentra en MP 13-14. Lophiodontidae indet. de Casaseca se asemeja a Lophiaspis occitanicus (Desmarest, 1822), género del Eoceno medio europeo que también está presente en algunos yacimientos prepirenaicos de la misma edad (Checa, 1994).

Una edad MP 13-14 también parece deducirse de la presencia en Casaseca del género Pachynolophus. Aunque este género se encuentra a lo largo de todo el Eoceno medio, y alcanza la parte inferior del Eoceno superior, la lofodoncia y el desarrollo de $\mathrm{M} / 3$ son intermedios entre las especies del inicio del Eoceno medio y las del superior (ver Remy, 1972).

Por otra parte, la presencia del género Plagiolophus, aunque se trate de una forma muy primitiva, implica una edad mínima MP 13, ya que dicho género se señala por 
primera vez en el nivel de Geiseltal OMK (Franzen y Haubold, 1986a y b, 1987). También los escasos restos de Palaeotheriidae, representados por premolares primitivos, abogan por esta edad, ya que el género Palaeotherium aparece en el nivel MP 13.

Una edad similar a la establecida a partir de los Perisodáctilos se deduce del estudio de los micromamíferos de los yacimientos de Santa Clara, El Viso-Sanzoles y Jambrina. Los Roedores, representados por el Ischyromidae Microparamys sp. y Zamoramys extraneus, posible Chapatímido (Peláez-Campomanes et al., 1989; Peláez-Campomanes, 1992; PeláezCampomanes y López-Martínez, 1996), no permiten más precisión biocronológica. La presencia en Santa Clara del Primate Adápido Anchomomys cf. stehlini, concuerda con la edad deducida del estudio de los Perisodáctilos, ya que Anchomomys stehlini Gingerich, 1977, está presente en Bouxwiller (MP 13) y Egerkingen (MP 14). El resto de micromamíferos encontrados en Santa Clara, El VisoSanzoles y Jambrina, con Marsupiales, cf. Anagalida, Proteuterios, Dichobúnidos y Nyctitéridos, no aportan más información biocronológica pues su atribución sistemática está aún pendiente (Peláez-Campomanes et al., 1989).

Con anterioridad, Roman y Royo (1922) y Roman (1923), basándose en Lophiodontidae, situaron Corrales en el "Luteciense medio", lo cual coincide con los resultados anteriores.

\section{Parte superior del Eoceno medio (Bartoniense medio-superior, MP 15-16)}

Yacimientos: Caenes, San Morales, Mazaterón, Fuentesaúco, Deza I, Miñana y Babilafuente (Fig. 2).

Los cinco primeros han liberado macromamíferos, especialmente Perisodáctilos, mientras que los yacimientos de Miñana y Babilafuente han proporcionado exclusivamente micromamíferos. Entre todos ellos destaca el yacimiento de Mazaterón, tanto por tener la fauna de mamíferos más diversificada de los yacimientos estudiados, como por su aportación a la bioestratigrafía y biogeografía de la Cuenca del Duero (Cuesta y Jiménez, 1994).

Las asociaciones de Perisodáctilos de esta época se diferencian netamente de las de los yacimientos anteriores, quedando ejemplificadas por la de Mazaterón:

* disminución de la diversidad de Lophiodontidae, con una sola forma, que pertenece a las denominadas especies "gigantes".

* coexistencia de Lophiodontidae con líneas más modernas e hipsodontas de Equoidea:

- Pachynolophinae: Paranchilophus; en San Morales cf. Anchilophus.

- Plagiolophinae: Plagiolophus mazateronensis, Plagiolophus sp. y Leptolophus sp.

- Palaeotheriidae: Palaeotherium giganteum, Cantabrotherium casanovasae y Franzenium durense.

Esta fauna de Perisodáctilos está compuesta por formas desconocidas en el resto de Europa así como en las localidades surpirenaicas, por lo que resulta difícil correlacionarla bioestratigráficamente con los niveles de referencia europeos.
Además, la mayor parte de estos Perisodáctilos tienen en común una marcada hipsodoncia, que se considera un carácter evolucionado y general durante el Eoceno superior europeo (ver Russell et al., 1982 y Franzen, 1968), combinado con una serie de rasgos primitivos que son más propios de las formas del Eoceno medio europeo, lo cual dificulta aún más la datación de estas faunas.

Inicialmente, la posición estratigráfica de Mazaterón (Cuesta, 1991, 1992b, 1993a; Cuesta y Jiménez, 1994) se basó en la estrecha relación entre su fauna de Perisodáctilos y la de Llamaquique (Cuenca de Oviedo; Casanovas y Santafé, 1987, 1989 y 1991a; Casanovas et al., 1991), ya que en ambos existen los géneros endémicos Cantabrotherium, Franzenium y Paranchilophus. La comparación entre las formas de Mazaterón y Llamaquique parece indicar que el primero es más antiguo, ya que Paranchilophus remyi de Mazaterón tiene menos molarizado el $\mathrm{P} 4 / 4$, lo cual es considerado generalmente como primitivo en Equoidea, y Cantabrotherium casanovasae y Franzenium durense de Mazaterón muestran en varios caracteres un estadio más primitivo que $C$. truyolsi Casanovas y Santafé, 1987 y $F$. tetradactylum Casanovas y Santafé, 1989, de Llamaquique. Teniendo en cuenta que Llamaquique fue situado inicialmente en la parte superior del Eoceno superior (Casanovas y Santafé, 1987), a Mazaterón se le atribuyó una edad entre la parte superior del Eoceno medio y la parte inferior del Eoceno superior. Sin embargo, recientemente Casanovas et al. (1991) bajan considerablemente la edad de Llamaquique, situándolo entre MP16 y 17, por lo que Mazaterón se situaría por debajo del límite Eoceno medio-Eoceno superior. El hallazgo reciente de Lophiodontidae en Mazaterón (Cuesta, 1996) ha aportado una mayor precisión a la edad del yacimiento, descartando su pertenencia al Eoceno superior. Además, la profusión de Equoidea relativamente modernizados e hipsodontos es un fenómeno general al final del Eoceno medio, coincidiendo con el declive de Lophiodontidae; en dicha época los últimos representantes de esta familia conviven con formas más modernas de Equoidea, como podemos observar en las asociaciones de Perisodáctilos de Robiac, Le Bretou y Creech Barrow (Sudre, 1969; Hooker, 1986; Remy, 1988). Estas faunas difieren por lo tanto de las correspondientes al Eoceno superior europeo, como las de Euzèt, Fons, etc. (Depéret, 1917; Remy, 1967; Franzen, 1968; Russell et al., 1982).

Otros argumentos están igualmente a favor de situar estas faunas al final del Eoceno medio. Por un lado está la posesión de varios rasgos primitivos en Palaeotherium giganteum y Plagiolophus mazateronensis, que los acercan a especies del Eoceno medio europeo. Por otro, la presencia del género Leptolophus, conocido sólo en algunos yacimientos franceses de los niveles 15-16 (Remy, 1965 y 1988; Sudre, 1969) y desconocido en el Eoceno superior.

La posición biocronológica deducida del estudio de los micromamíferos de Mazaterón y Miñana concuerda básicamente con los resultados anteriores. Inicialmente 
fueron correlacionados con el nivel de Fons 4, es decir Ludiense inferior, MP 17 (Peláez-Campomanes et al., 1989; Vianey-Liaud et al., 1994). Posteriormente PeláezCampomanes (1996) sugiere una edad MP 16, basándose en la presencia de Sciuroides cf. siderolithicus y Pseudoltinomys crebrum, que se asemejan a las especies de estos géneros presentes en el Bartoniense mediosuperior europeo.

La presencia en Miñana de Amphiperatherium cf. minutum y Saturninia cf. mamertensis (PeláezCampomanes et al., 1989) no aporta más precisiones biocronológicas.

Los Primates son escasamente conocidos y están representados en Mazaterón, Miñana y Caenes por Adápidos y Omómidos que parecen diferentes a los europeos, por lo que no pueden correlacionarse con ellos (Moyà y Khöler, 1992).

Los Artiodáctilos encontrados en Mazaterón y Caenes (Cuesta, 1993b, 1997 y 1998) están representados por varias formas cuyas atribuciones genérica o específica están pendientes, pero no están en desacuerdo con lo expuesto para Perisodáctilos y Roedores, ya que están presentes las familias Dacrytheridae, Xiphodontidae y Anoplotheriidae, al igual que en el Eoceno medio y el superior europeos.

Por su parte, el yacimiento de Babilafuente (Salamanca), con Remys aff. minimus ha sido datado como MP 16 (López-Martínez, 1984; PeláezCampomanes et al., 1989).

\section{Eoceno superior (MP 17)}

Único yacimiento: Deza II (Fig. 2).

En este yacimiento sólo se han determinado los Roedores Glamys priscus y Theridomys euzetensis (Peláez-Campomanes, 1996); la presencia de éste último lo sitúa en MP 17.

\section{Eoceno superior-Oligoceno inferior? (MP?)}

Único yacimiento: Molino del Pico (Fig. 2).

En el yacimiento de Molino del Pico se han determinado escasos restos atribuibles a un Palaeotheriidae muy hipsodonto, con hipsodoncia mayor que en los conjuntos anteriores, y un Plagiolophus caracterizado por una gruesa capa de cemento, lo cual lo diferencia claramente de todos los anteriores y lo relaciona con las especies europeas de la transición Eoceno-Oligoceno, como P. fraasi (Meyer, 1852), P. majus Brunnet y Yehenne, 1989, y P. javali (Filhol, 1877), tal y como son consideradas en la revisión de Brunet y Jehenne (1989). Una edad Eoceno superiorOligoceno inferior fue sugerida por Jiménez (1983) y por Jiménez et al. (1983), con base en argumentos geológicos y paleontológicos.

\section{BIOGEOGRAFÍA}

A pesar de un conocimiento aún muy imperfecto, el estudio de las faunas de mamíferos del Eoceno de la Cuenca del Duero ha aportado datos importantes

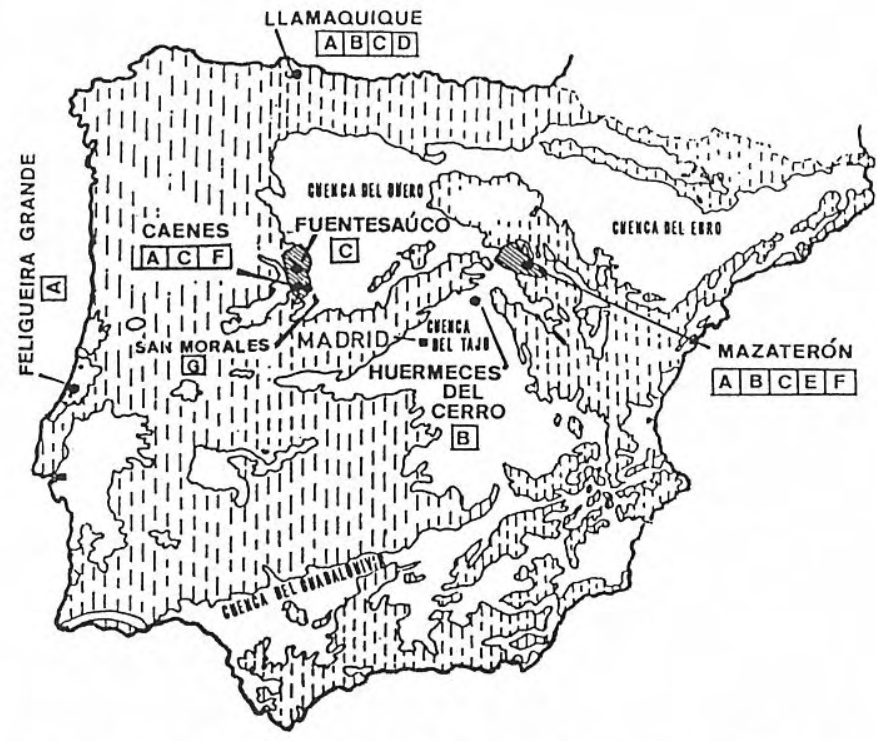

Figura 3. Distribución de los Perisodáctilos endémicos de la región occidental ibérica. En blanco: cuencas terciarias ibéricas; rayado oblicuo: sector paleógeno suroccidental de la Cuenca del Duero y subcuenca de Almazán. Géneros endémicos: A. Paranchilophus, B. Cantabrotherium, C. Franzenium. Especies endémicas: D. Palaeotherium llamaquiquense, E. Palaeotherium giganteum, F. Plagiolophus mazateronensis, G. Lophiodon sanmoralense.

referentes a la biogeografía de la cuenca y de la Península Ibérica durante el Eoceno medio, en especial de los Perisodáctilos y Roedores.

En las faunas de Perisodáctilos de la parte media del Eoceno medio (MP 13-14) no se han observado diferencias marcadas con las el resto de Europa occidental, si bien el conocimiento actual de este grupo es más bien escaso (Cuesta, 1991, 1992b, 1993a, 1994a, b y c). No obstante, parece perfilarse una cierta diferenciación biogeográfica de la región durante esta época, como lo demuestran la presencia de Plagiolophus casasecaensis, desconocida fuera de la Cuenca del Duero, y las posibles diferencias a nivel específico de Lophiodon cf. tapirotherium, Paralophiodon aff. isselense y Pachynolophus sp. con sus correspondientes europeos. En Roedores, Peláez-Campomanes y LópezMartínez (1996) han descrito Zamoramys extraneus en Sanzoles y Santa Clara, nuevo género de afinidades inciertas y de morfología muy cercana a los Chapattímidos del Eoceno medio de India y Pakistán (ver también Peláez-Campomanes et al., 1989). Según los citados autores, este hallazgo contradice el supuesto aislamiento de Europa durante el Eoceno medio, proporcionando evidencias de posibles intercambios en Eurasia durante dicha época. En esta misma línea está la presencia de cf. Anagalida también en Santa Clara, con semejanzas con los Anagálidos de China (PeláezCampomanes et al., 1989).

Por el contrario, las faunas de mamíferos de la parte superior del Eoceno medio de la Cuenca del Duero (MP 
15-16), en especial las de Perisodáctilos (Cuesta, 1988, 1991, 1992b, 1993a, 1994a, b y c, 1996; Jiménez et al., 1989 y 1994; Cuesta et al., 1993; Cuesta y Jiménez, 1994), muestran un notable carácter endémico respecto a las de Europa occidental y a las estrechamente relacionadas de la zona oriental ibérica (área surpirenaica y Baleares). Este hecho es especialmente patente en el yacimiento de Mazaterón (Subcuenca de Almazán), donde las ocho formas de Perisodáctilos presentes difieren significativamente de las de los yacimientos clásicos del occidente europeo. También poseen formas endémicas de Perisodáctilos Caenes, San Morales, Deza I y Fuentesaúco.

Las faunas de Perisodáctilos de estos yacimientos están formadas por géneros o especies desconocidos en Europa occidental y región oriental ibérica, que son exclusivos de la Cuenca del Duero o sólo aparecen en ciertos yacimientos ibéricos occidentales, concretamente de las cuencas de Oviedo (Llamaquique; Casanovas y Santafé, 1987, 1989 y 1991a), Tajo (Huérmeces del Cerro; Casanovas y Santafé, 1987) y Mondego (Feligueira Grande; Antunes, 1995), esta última en Portugal.

Los Perisodáctilos endémicos de los yacimientos ibéricos occidentales considerados globalmente son los siguientes (Fig. 3):

* a nivel genérico: Cantabrotherium, Franzenium y Paranchilophus.

* a nivel específico: Cantabrotherium truyolsi, $C$. casanovasae, Franzenium tetradactylum, F. durense, Paranchilophus remyi, Plagiolophus mazateronensis, Palaeotherium llamaquiquense Casanovas y Santafé, 1991, P. giganteum, Lophiodon sanmoralense.

Leptolophus sp., Plagiolophus sp. de Mazaterón y San Morales, por el momento escasamente documentados, parecen ser igualmente formas diferentes a las conocidas de sus respectivos géneros en Europa.

Es notable el hecho de que en la mayoría de estas formas, pertenecientes a distintos grupos taxonómicos de Perisodáctilos, se combinen una serie de características primitivas, especialmente en los premolares, con una acusada tendencia a la hipsodoncia; tal combinación es desconocida en los Perisodáctilos del Eoceno europeo.

La ausencia de una serie de géneros y especies de Perisodáctilos que son elementos faunísticos normales en los yacimientos de Europa occidental de MP 15-16 pone aún más de relieve la individualidad de las faunas de la región ibérica occidental. Las faunas de Perisodáctilos del final del Eoceno medio y también del principio del Eoceno superior de Europa occidental se caracterizan por la presencia de:

- Palaeotherium típicos, con más o menos avanzada molarización de los premolares

- Anchilophus

- Plagiolophus annectens (Owen, 1847)

- Lophiotherium

- Lophiodon lautricense Noulet, 1851.

Como ejemplos de tales asociaciones faunísticas están los yacimientos franceses de Euzèt, Fons, Robiac, (Depéret, 1917; Remy, 1967; Franzen, 1968; Sudre,
1969; Hartenberger, 1970), los surpirenaicos de Sossís y Roc de Santa (Casanovas, 1975; Casanovas y Santafé, 1982; Casanovas et al., 1998) y algunos otros de Baleares (Bauza, 1946; Hugueney y Adrover, 1982).

Casanovas y Santafé $(1987,1989$ y 1991a y b) fueron los primeros autores en poner de relieve un notable carácter endémico de los Perisodáctilos del Eoceno ibérico occidental, a partir del establecimiento en Llamaquique (Cuenca de Oviedo) de los tres nuevos géneros de Equoidea Paranchilophus, Cantabrotherium y Franzenium. La presencia de éstos, junto a otras formas endémicas a nivel específico, en yacimientos de las cuencas de Oviedo, Duero, Tajo y Mondego (Portugal) (Fig. 3) aboga por una diferenciación biogeográfica de la región ibérica occidental con respecto al resto de Europa occidental. Ello significa que al final del Eoceno medio la Península Ibérica estuvo dividida en dos áreas claramente diferenciadas, una oriental junto con Baleares, similar al resto de Europa occidental, y otra occidental. Tal diferenciación fue sugerida por Casanovas y Santafé (1991b) y Casanovas y Moyà (1992) con base fundamentalmente en la fauna de Llamaquique (Cuenca de Oviedo).

En Europa occidental se ha puesto de manifiesto una cierta individualización en subprovincias durante el Eoceno superior, ya que se han descrito diferencias regionales en Roedores, Artiodáctilos y Primates (Hartenberger, 1973a; Sudre, 1974 y 1978; SchmidtKittler y Vianey-Liaud, 1975; Vianey-Liaud, 1976); no obstante, tal diferenciación nunca es tan acusada como la que observamos entre las faunas de Perisodáctilos del occidente peninsular y el resto de Europa occidental.

Un grado de endemismo similar al de Perisodáctilos se ha observado en Roedores de la parte superior del Eoceno medio, si bien sus faunas son menos diversas (Peláez-Campomanes, 1992, 1993 y 1996; Vianey-Liaud et al., 1994). En Mazaterón y Miñana están presentes Sciuroides cf. siderolithicus, Pseudoltinomys crebrum y Pairomys ibericus, las dos últimas desconocidas en Europa, y destacando el género endémico Payromys. En Babilafuente se ha determinado Remys aff. minimus (Peláez-Campomanes et al., 1989). Los yacimientos europeos de MP 16, como Creech Barrow, Robiac y Le Bretou muestran una mayor diversidad de Roedores y una serie de géneros ausentes de las faunas del Duero, como Elfomys, Paradelomys, Suevosciurus, Treposciurus, así como varias especies (Hartenberger, 1973b y 1988; Hooker, 1986; Hartenberger et al., 1974). La posesión de un patrón similar a los Perisodáctilos, es decir, morfología dentaria primitiva en combinación con dientes hipsodontos patentiza aún más la singularidad de las faunas de la Cuenca del Duero.

Si bien el estudio de los Primates se encuentra todavía en una fase inicial, Moyà y Köhler (1992) ponen de manifiesto diferencias claras con el resto de Europa.

Los Artiodáctilos presentan semejanzas con los europeos pero por el momento no pueden asignarse a ninguna especie conocida (Cuesta, 1993b, 1997 y 1998).

En el Eoceno superior los escasos datos paleontológicos impiden precisiones de tipo biogeográfico. 
Para explicar el carácter endémico de las faunas de Perisodáctilos y otros mamíferos de la zona occidental Ibérica en la parte superior del Eoceno medio, se ha aducido por un lado la existencia de alguna barrera geográfica que habría aislado dicha región (Casanovas y Santafé, 1987, 1989 y 1991a; Cuesta, 1992a). En este sentido, las reconstrucciones paleogeográficas del Eoceno ibérico (López-Martínez, 1989) muestran la existencia de mares epicontinentales que unieron en mayor o menor grado el Cantábrico y el Mediterráneo, aislando la parte occidental de la península Ibérica de la nororiental. Los esquemas paleogeográficos sobre la evolución geográfica durante el Eoceno, establecidos recientemente para el Terciario de la Península, no están en desacuerdo con este planteamiento (para un resumen y referencias ver LópezMartínez, 1989). Por otro lado, hay que tener en cuenta razones de tipo ecológico, relacionadas con la constancia de un mismo patrón dentario en los Perisodáctilos Equoidea, que no poseen las formas de Europa occidental: morfología dentaria primitiva combinada con una dentición muy hipsodonta. Ello sugiere unas condiciones ecológicas más severas que en el resto de Europa (Jiménez et al., 1989, Casanovas y Santafé, 1989 y 1991a; Cuesta, 1991, 1992b, 1993a, 1994a, b y c). Para Peláez-Campomanes (1992 y 1996), la presencia de un patrón dentario similar en Roedores es también reflejo de unas especiales condiciones ecológicas, que parecen corresponder a la existencia de hábitats abiertos.

Por otro lado, la intermitencia de los contactos entre África y Europa occidental es otro fenómeno a tener en cuenta en la biogeografía de la zona occidental ibérica. Argumentos tectónicos (Dercourt et al., 1986; Srivastava et al., 1990) recopilados por Casanovas y Santafé (1991b) y Casanovas y Moyà (1992) abogan por movimientos de la placa Ibérica que habrían propiciado intercambios faunísticos entre ambas masas continentales que, unido a posibles etapas de aislamiento de la península, habrían tenido una gran influencia sobre el carácter endémico de sus faunas. Casanovas y Santafé (1991b) y Casanovas y Moyà (1992) recopilan otra serie de argumentos paleontológicos, basados fundamentalmente en recientes hallazgos en el Norte de África, que están a favor de conexiones faunísticas África-Europa. Gheerbrant (1990) ha lanzado la hipótesis de la existencia de dos eventos mayores de intercambio faunístico entre Europa y África, uno en el Paleoceno, próximo al límite con el Cretácico, y otro cercano al límite Paleoceno-Eoceno. El mismo autor (Gheerbrant, 1987, fig.3) señala que una de las vías de dispersión pudo haber sido la Península Ibérica. Más recientemente, Hartenberger et al. (1997) postulan la existencia de intercambios entre África del Norte y Europa en el límite Paleoceno-Eoceno, mientras que Mahboubi et al. (1997) suponen tres eventos de intercambio África-regiones nortetianas: ante-thanetiense, Eoceno inferior y Eoceno medio.

A la luz de estos datos parece perfilarse el posible origen africano de varios grupos faunísticos de mamíferos presentes en el Eoceno europeo. Tal idea se ha postulado por ejemplo para los Adápidos y los Notárctidos, entre los Primates (Gingerich, 1977; Franzen, 1987), así como para los Artiodáctilos (ver por ejemplo Estravis y Russell, 1989), si bien para estos últimos no faltan opiniones que abogan por un origen asiático (ver referencias en Averianov, 1996). También varios autores han lanzado la hipótesis de un origen africano para los Perisodáctilos, Hyracoidea incluidos o no (ver por ejemplo: McKenna, 1975; Fischer, 1986; Wible, 1986; MacFadden, 1988; Prothero y Schoch, 1989; Casanovas y Santafé, 1991b). Casanovas y Santafé (1982, 1987 y 1991b) y Franzen (1989) propugnan la posible procedencia africana de Palaeotheriidae (en el sentido de Franzen, 1968), de origen actualmente desconocido; según tales autores dicho grupo habría inmigrado primeramente a la Península Ibérica y posteriormente al resto de Europa. La ideas anteriores están apoyadas por la inclusión de los Hiracoideos en los Perisodáctilos (Fischer, 1989). Dicho grupo esencialmente africano presenta numerosas similitudes con los Paleotéridos.

En conclusión, la combinación de posibles contactos faunísticos con África y Europa, ciertas etapas de aislamiento, unido a unas especiales condiciones ecológicas, han podido ser los factores determinantes de las marcadas peculiaridades de las faunas de mamíferos del Eoceno de la Cuenca del Duero, y en general de la región ibérica occidental.

\section{AGRADECIMIENTOS}

A los doctores Miguel Telles Antunes (Facultad de Ciencias y Tecnología, Universidad de Lisboa) y $\mathrm{M}^{\mathrm{a}}$ Lourdes Casanovas-Cladellas y José Vicente Santafé-Llopis (Instituto Paleontológico M. Crusafont, Sabadell, Barcelona). A Angel Cuesta, que realizó los dibujos. A Olatz Matía, por su revisión del Abstract.

\section{BIBLIOGRAFÍA}

Aguilar, J.P., Legendre, S. et Michaux, J. (Eds.) 1997. Actes du Congrès BiochroM'97, Montpellier, 14-17 Avril. Biochronologie mammalienne du Cénozoïque en Europe et domaines reliés. Mémoires et Travaux de l'Institut de Montpellier, École Practique des Hautes Études, 21, 1818.

Alonso-Gavilán, G. 1981. Estratigrafía y Sedimentología del Paleógeno del borde SO de la Cuenca del Duero (Provincia de Salamanca). Tesis Doctoral, Universidad de Salamanca, 1-435.

Antunes, M. 1995. On the Eocene Equid (Mammalia) from Feligueira Grande, Portugal, Paranchilophus lusitanicus (Ginsburg, 1965). Taxonomic status, stratigraphic and paleogeographical meaning. Comunicaçoes Instituto Geológico e Mineiro, 81, 57-72.

Antunes, M., Casanovas, M.L., Cuesta, M.A., Checa, L., Santafé, J.V. and Agustí, J. 1997. Eocene Mammals from Iberian Peninsula. In: Actes du Congrès BiochroM'97 (Eds. J.P. Aguilar, S. Legendre et J. Michaux). Mémoires et Travaux de l'Institut de Montpellier, École Practique des Hautes Études, 21, 337-352. 
Armenteros, I., Dabrio, C.J., Guisado, R. y Sánchez de Vega, A. 1989. Megasecuencias sedimentarias del Terciario del borde oriental de la cuenca de Almazán (Soria-Zaragoza). Stvdia Geologica Salmanticensia, volumen especial 5, 107-127.

Averianov, A. 1996. Artiodactyla from the early Eocene of Kyrgyzstan. Palaeovertebrata, 25 (2-4), 359-369.

Aymard, A. 1846. Essai monographique sur un nouveau genre de mammifère fossile trouvé dans la Haute-Loire et nommé Entelodon. Annales de la Societé Agraire du Puy, 12, 241-267.

Bauza, J. 1946. Hallazgo de Lophiotherium cf. cervulum Gervais, en los lignitos de Lloseta. (Contribución al conocimiento de la Paleontología de Mallorca). Boletín Real Sociedad Española de Historia Natural, 44, 566569.

BiochroM'97, 1997. Synthèses et tables de corrélations. Syntheses and correlation tables. In: Actes du Congrès BiochroM'97 (Eds. J.P. Aguilar, S. Legendre et J. Michaux). Mémoires et Travaux de l'Institut de Montpellier, École Pratique des Hautes Études, 21, 769805.

Brunet, M. et Jehenne, Y. 1989. Révision des genres Plagiolophus Pomel, 1847 et Paloplotherium Owen, 1848, Mammalia, Palaeotheriidae, du Paléogène d'Europe; intérêt biochronologique. Annales de Paléontologie (Vertébrés, Invertébrés), 75 (1), 23-52.

Calderón, S. 1902. Noticia del descubrimiento de huesos fósiles en una caliza terciaria de Villamayor (Salamanca). Boletín de la Real Sociedad Española de Historia Natural, 2, 230-231.

Casanovas, M.L. 1975. Estratigrafía y Paleontología del yacimiento ludiense de Roc de Santa (Área del NogueraPallaresa). Paleontologia i Evolució, 10, 1-158.

Casanovas, M.L. y Moyà, S. 1992. La sucesión de faunas de mamíferos durante el Paleógeno europeo. In: Paleontología de Vertebrados. Faunas y filogenia, aplicación y sociedad (Ed. H. Astibia). Servicio editorial, Universidad del País Vasco, Bilbao, 187-234.

Casanovas, M.L. y Santafé, J.V. 1982. Los Palaeotheriidae (Perissodactyla, Mammalia) de talla media del yacimiento ludiense de Sossís (Tremp, Lérida). Paleontologia i Evolució, 17, 15-50.

Casanovas, M.L. et Santafé, J.V. 1987. Cantabrotherium truyolsi nov. gen. nov. sp. (Palaeotheriidae, Perissodactyla), un exemple d'endémisme dans le Paléogène ibérique. Münchener Geowissenschaftliche Abhandlungen, (A) 10, 243-252.

Casanovas, M.L. y Santafé, J.V. 1989. Dos nuevos Paleotéridos (Perissodactyla, Mammalia) del yacimiento eocénico de Llamaquique (Oviedo). Trabajos de Geología, Universidad de Oviedo, 18, 337-352.

Casanovas, M.L. y Santafé, J.V. 1991a. Los Paleotéridos (Perissodactyla, Mammalia) de Llamaquique (Oviedo, España). In: El yacimiento eocénico de Llamaquique (Oviedo, España) y su contenido paleontológico (Coords. M.L. Casanovas, J.V. Santafé y J. Truyols). Boletín de Ciencias Naturales, Instituto de Estudios Asturianos, 41, 101-188.

Casanovas, M.L. y Santafé, J.V. 1991b. Hipótesis sobre migraciones faunísticas en el Eoceno ibérico. In: $E l$ yacimiento eocénico de Llamaquique (Oviedo, España) y su contenido paleontológico (Coords. M.L. Casanovas, J.V. Santafé y J. Truyols). Boletín de Ciencias Naturales, Instituto de Estudios Asturianos, 41, 243-252.

Casanovas, M.L., Jiménez, E., Martín, C., Moyà, S., Santafé, J.V. y Truyols, J. 1991. Consideraciones sobre la edad del yacimiento eocénico de Llamaquique (Oviedo, España). In: El yacimiento eocénico de Llamaquique (Oviedo, España) y su contenido paleontológico (Coords. M.L. Casanovas, J.V. Santafé y J. Truyols). Boletín de Ciencias Naturales, Instituto de Estudios Asturianos, 41, 253-261.

Casanovas, M.L., Checa, L. y Santafé, J.V. 1998. Los Perisodáctilos del yacimiento ludiense de Sossís (Cuenca Prepirenaica, Lleida, España). In: Geología y Paleontología del Eoceno de la Pobla de Segur (Lleida) (Eds. N. López, J. Civis, M.L Casanovas y R. Daams). Universitat de Lleida, Institut d'Estudis Ilerdencs, 235267.

Checa, L. 1994. Los Perisodáctilos (Ungulata, Mammalia) del Eoceno Catalán. Tesis Doctoral, Universidad Central de Barcelona (inédita), 2 vols, texto, 1-357.

Checa, L. y Casanovas, M.L. 1990. El Eoceno Español: los yacimientos y sus faunas. Paleontologia i Evolució, 23, 17-39.

Colmenero, J.R., Manson, M., García, J.C. y Vargas, I. 1982. Depósitos aluviales cíclicos en el Paleógeno del borde N. de la Cuenca del Duero. Temas Geológicos y Mineros, IGME, 6(1), 185-196.

Corrochano, A. y Carballeira, J. 1983. Las depresiones del borde suroccidental de la Cuenca del Duero. In: Libro Jubilar de J.M Ríos, Geología de España, 2, IGME, 513521.

Crochet, J.Y. 1979. Diversité systématique des Didelphidae (Marsupialia) européens tertiairs. Geobios, 12, 365-378.

Crusafont, M. y Truyols, J. 1957. Algunas precisiones sobre la edad y extensión del Paleógeno de las provincias de Salamanca y Zamora. Cursos y Conferencias del Instituto Lucas Mallada, 9, 83-85.

Cuesta, M.A. 1988. Perisodáctilos del Eoceno de la Cuenca del Duero. IV Jornadas de Paleontología, Resúmenes de las comunicaciones, Salamanca, 34.

Cuesta, M.A. 1991. Perisodáctilos del Eoceno de la Cuenca del Duero. Tesis Doctoral, Facultad de Biología, Universidad de Salamanca (inédita), 2 vols., texto 1-322.

Cuesta, M.A. 1992a. Creodontos del Paleógeno de Castilla y León. In: Vertebrados fósiles de Castilla y León (Coord. E. Jiménez). Museo de Salamanca, 101-104.

Cuesta, M.A. 1992b. Perisodáctilos del Paleógeno de Castilla y León. In: Vertebrados fósiles de Castilla y León (Coord. E. Jiménez). Museo de Salamanca, 111120.

Cuesta, M.A. 1992c. Nota preliminar sobre los Artiodáctilos del yacimiento de Mazaterón (Eoceno superior, Soria). VIII Jornadas de Paleontología, Resúmenes de las comunicaciones, Barcelona, 41-42.

Cuesta, M.A. 1993a. Los Palaeotheriidae (Perissodactyla, Mammalia) del Eoceno de la Cuenca del Duero (Castilla y León, España). Estudios Geológicos, 49, 87-109. 
Cuesta, M.A. 1993b. Cuatro formas de Artiodactyla del yacimiento Eoceno de Mazaterón (Soria, Cuenca del Duero, España). Treballs del Museu de Geologia de Barcelona, 3, 81-90.

Cuesta, M.A. 1994a. Los Lophiodontidae (Perissodactyla, Mammalia) del Eoceno de la Cuenca del Duero (Castilla y León, España). Stvdia Geologica Salmanticensia, 29, 23-65.

Cuesta, M.A. 1994b. Los Plagiolophinae nov. subfam. (Perissodactyla, Mammalia) del Eoceno de la Cuenca del Duero (Castilla y León, España). Estudios Geológicos, 50, 253-279.

Cuesta, M.A. 1994c. Los Pachynolophinae (Equoidea, Perissodactyla, Mammalia) del Eoceno de la Cuenca del Duero (Castilla y León, España). Stvdia Geologica Salmanticensia, 30, 21-63.

Cuesta, M.A. 1996. Primeros hallazgos de Lophiodontidae (Perissodactyla, Mammalia) en el yacimiento eocénico de Mazaterón (Cuenca del Duero, España): implicaciones bioestratigráficas. Stvdia Geologica Salmanticensia, 32, 39-48.

Cuesta, M.A. 1997. Leptotheridium sp., primer Artiodáctilo del yacimiento eocénico de Caenes (Cuenca del Duero, provincia de Salamanca, Castilla y León, España). XIII Jornadas de Paleontología, Resúmenes de las comunicaciones, La Coruña, 162-164.

Cuesta, M.A. 1998. Presencia de Leptotheridium (Dacrytheriidae, Artiodactyla, Mammalia) en el yacimiento eocénico de Caenes (Cuenca del Duero, Castilla y León, España). Stvdia Geologica Salmanticensia, 34, 69-78.

Cuesta, M.A. y Jiménez, E. 1994. Síntesis del Paleógeno del borde oriental de la Cuenca de Almazán (Soria): vertebrados de Mazaterón. Stvdia Geologica Salmanticensia, 29, 157-170.

Cuesta, M.A., Jiménez, E. y Gil, S. 1993. Fuentesaúco: nuevo yacimiento de Vertebrados en el límite Eoceno medio-Eoceno superior, de la provincia de Zamora. IX Jornadas de Paleontología, Resúmenes de las comunicaciones, Málaga, 91-92.

Cuvier, G. 1804. Sur les espèces d'animaux dont proviennent les os fossiles répandus dans la pierre à platre des environs de Paris. Annales du Muséum d'Histoire Naturelle, 3, 275-303.

Cuvier, G. 1812. Recherches sur les ossements fossiles. $1^{\text {a }}$ ed., Paris.

Cuvier, G. 1822. Recherches sur les ossements fossiles. $2^{\mathrm{a}}$ ed., Paris, 3, Xiphodon, 60, 69, 104, 137, 161, 16, 176, 185, 191, 198, 206, 210, 228, 248.

De La Peña, A. 1992. Peces fósiles de Castilla y León. In: Vertebrados fósiles de Castilla y León (Coord. E. Jiménez). Museo de Salamanca, 43-45.

Dedieu, P. 1976. Les Tapiroidea (Mammalia, Perissodactyla) du gisement lutétien d'Issel (Aude). Thèse Doctorale troisième cycle, Université de Poitiers, 1-179.

Dedieu, P. 1977a. Le Tapiroidea à denture rhinocérotoide du gisement lutétien d'Issel (Aude): Paralophiodon isselensis (Fischer, 1829). Bulletin de la Société d'Histoire Naturelle, Toulouse, 113 (1-2), 32-39.
Dedieu, P. 1977b. Sur la systématique des Tapiroidea (Mammalia) de l'Eocène européen. Comptes Rendus de l'Académie des Sciences, Paris, D, 2219-2222.

Depéret, Ch. 1917. Monographie de la faune de mammifères fossiles du Ludien inférieur d'Euzèt-les-Bains (Gard). Annales de l'Université de Lyon (Sciences, Médécine), 40, 1-274.

Dercourt, J., Zonenshain, L.P., Ricou, L.E., Kazmin, V.G., Lepichon, X., Knipper, A.M., Grandjacquet, C., Sborshikov, I.M., Geyssant, J., Lepvrier, C., Pechersky, D.H., Boulin, J., Sibuet, J.C., Savostin, L.A., Sorokhtin, O., Westphal, M., Bazhenov, M.L., Lauer, P.J. and BijuDuval, B. 1986. Geological evolution of the Tethys belt from the Atlantic to the Pamirs since the Lias. Tectonophysics, 123, 241-315.

Desmarest, A. 1822. Mammalogie ou description des espèces de mammifères. Encyclopédique méthodique, $4^{\mathrm{a}}$ ed., 126, 1-556.

Estravis, C. et Russell, D.E. 1989. Découvert d'un nouveau Diacodexis (Artiodactyla, Mammalia) dans l'Eocène inférieur de Silveirinha, Portugal. Palaeovertebrata, 19 (1), 29-44.

Fahlbush, V. 1976. Report on the International Symposium on mammalian stratigraphy of the European Tertiary in Munich, April 11-14, 1975. Newsletter of Stratigraphy, Leiden, 5 (21), 160-167.

Filhol, H. 1877. Recherches sur les phosphorites de Quercy. Étude des fossiles qu'on y recontre et spécialement des mammifères. Annales des Sciences Géologiques, 8, 1340.

Fischer, J.B. 1829. Synopsis mammalium. Stuttgart, 1-752.

Fischer, M.S. 1986. Die Stellung der Schliefer (Hyracoidea) im phylogenetischen System der Eutheria. Courier Forschungsinstitut Senckenberg, Frankfurt, 84, 1-132.

Fischer, M.S. 1989. Hyracoids, the sister-group of perissodactyls. In: The evolution of Perissodactyls (Eds. D.R. Prothero \& R.M. Schoch). Oxford University Press, 37-56.

Franzen, J.L. 1968. Revision der Gattung Palaeotherium Cuvier, 1804 (Palaeotheriidae, Perissodactyla, Mammalia). Tesis Doctoral, Universität zu Freiburg, 2 vols., texto 1-181.

Franzen, J.L. 1987. Ein neuer Primat aus dem Mitteleozän der Grube Messel (Deutschland, S.-Hessen). Courier Forschungsinstitut Senckenberg, Frankfurt, 91, 151-187.

Franzen, J.L. 1989. Origin and Systematic position of the Palaeotheriidae. In: The evolution of Perissodactyls (Eds. D.R. Prothero \& R.M. Schoch). Oxford University Press, 102-108.

Franzen, J.L. and Haubold, H. 1986a. The Middle Eocene of European Mammalian Stratigraphy. Definition of the Geiseltalian. Modern Geology, 10, 159-170.

Franzen, J.L. und Haubold, H. 1986b. Revision der Equoidea aus den Eozänen Braunkholen des Geiseltales bei Halle. Palaeovertebrata, 16 (1), 1-34.

Franzen, J.L. and Haubold, H. 1987. The bioestratigraphic and palaeoecologic significance of the Middle Eocene locality Geiseltal near Halle (German Democratic Republic). Münchener Geowissenschaftliche Abhandlungen, A (10), 93-100. 
Garzón, G. y López-Martínez, N. 1978. Los Roedores fósiles de Los Barros (Avila). Datación del Paleógeno continental en el Sistema Central. Estudios Geológicos, 34, 571-575.

Gheerbrant, E. 1987. Les vertébrés continentaux de l'Adrar Mgorn (Maroc, Paléocène). Une dispersion de mammifères transtéthysienne aux environs de la limite Mésozoïque/Cénozoïque. Geodinamica Acta, 1(4-5), 233-246.

Gheerbrant, E. 1990. On the early biogeographical History of the African placentals. Historical Biology, 4 (2), 107 116.

Gil, S. 1992. Yacimientos de Vertebrados paleógenos de Castilla y León. In: Vertebrados fósiles de Castilla y León (Coord. E. Jiménez). Museo de Salamanca, 27-37.

Gingerich, P.D. 1977. New Species of Eocene Primates and the Phylogeny of European Adapidae. Folia Primatologica, 28, 60-80.

Guisado, R., Armenteros, I. y Dabrio, C.J. 1988. Sedimentación continental paleógena entre Almazul y Deza (Cuenca de Almazán Oriental, Soria). Stvdia Geologica Salmanticensia, 25, 67-85.

Hartenberger, J.L. 1970. Les Mammifères d'Egerkingen et l'histoire des faunes de l'Eocène d'Europe. Bulletin de la Société Géologique de France, sér.7, 12, 886-893.

Hartenberger, J.L. 1973a. Les Rongeurs de l'Eocène d'Europe; leur évolution dans leur cadre biogéographique. Bulletin du Muséum National d'Histoire Naturelle, Paris, série 3, 132, Sciences de la Terre, 24, 49-70.

Hartenberger, J.L. 1973b. Etude systématique des Theridomyoidea (Rodentia) de l'Eocène supérieur. Mémoire de la Société Géologique de France. Nouvelle Série, 117, 1-74.

Hartenberger, J.L. 1988. Le gisement du Bretou (Phosphorites du Quercy, Tarn-et-Garonne, France) et sa faune de vertébrés de l'Eocène supérieur. V Rongeurs. Palaeontographica, 205, 103-112.

Hartenberger, J.L., Sigé, B. et Sudre, J. 1974. La plus ancienne faune de Mammifères de Quercy: Le Bretou. Palaeovertebrata, 6, 177-196.

Hartenberger, J.L., Crochet, J.Y., Martínez, C., Feist, M., Godinot, M., Mannai, B., Marandat, B. et Sigé, B. 1997. Le gisement de Mammifères de Chambi (Eocène, Tunisie Centrale) dans son contexte géologique. Apport à la connaissance de l'évolution des Mammifères en Afrique. In: Actes du Congrès BiochroM'97 (Eds. J.P. Aguilar, S. Legendre et J. Michaux). Mémoires et Travaux de l'Institut de Montpellier, École Pratique des Hautes Études, 21, 263-274.

Hernández-Pacheco, E. 1915. Estratigrafía y Paleontología del Mioceno de Palencia. Memorias de la Comisión de Investigaciones Paleontológicas y Prehistóricas, 5, 1295.

Hernández-Pacheco, E. 1943. Observaciones respecto al Paleógeno continental hispánico. Las Ciencias, Madrid, 8 (3), 545-555.

Hooker, J.J. 1986. Bartonian Mammals (middle/late Eocene) of the Hampshire Basin, southern England. Bulletin of the British Museum Natural History, 39 (4), 1-478.
Hugueney, M. et Adrover, R. 1982. Le peuplement des Baleares (Espagne) au Paléogene. Geobios, Mémoire Spéciale, 6, 439-449.

Jaeger, J.J. 1971. La faune de mammifères lutétiéns de Bouxwiller (Bas Rhin) et sa contribution à l'élaboration d'une échelle de zones biochronologiques de l'Eocène européen. Bulletin Service Carte Géolique Alsace Loraine, 24 (2-3), 93-105.

Jiménez, E. 1970. Estratigrafía y Paleontología del borde suroccidental de la Cuenca del Duero. Tesis Doctoral, Universidad de Salamanca (inédita), 1-323.

Jiménez, E. 1971. Estratigrafía y Paleontología del borde suroccidental de la Cuenca del Duero. Resumen, Tesis Doctorales, Ciencias, 1969-1970, Acta Salmanticensia Ciencias, 37, 43-72.

Jiménez, E. 1983. Síntesis del Paleógeno Continental de la Cuenca del Duero. In: Libro Jubilar de J.M Rios, Geología de España, vol.2, IGME, 103-106.

Jiménez, E. 1992a. Las dataciones del Paleógeno de Castilla y León. In: Vertebrados fósiles de Castilla y León (Coord. E. Jiménez). Museo de Salamanca, 39-42.

Jiménez, E. 1992b. Quelonios fósiles de Castilla y León. In: Vertebrados fósiles de Castilla y León (Coord. E. Jiménez). Museo de Salamanca, 71-100.

Jiménez, E., Corrochano, A. y Alonso-Gavilán, G. 1983. El Paleógeno de la Cuenca del Duero. In: Libro Jubilar de J.M Rios, Geología de España, vol.2, IGME, 489-494.

Jiménez, E., Cuesta, M.A., Martín, S., Mulas, E., Pérez, E. y Jiménez, S. 1989. Primera nota sobre los vertebrados del Eoceno Superior de Mazaterón y Deza (Soria). Stvdia Geologica Salmanticensia, volumen especial 5, 59-66.

Jiménez, E., Cuesta, M.A. y Gil, S. 1994. Vertebrados fósiles del Eoceno de Fuentesaúco (Zamora). Stvdia Geologica Salmanticensia, 29, 7-21.

López-Martínez, N. 1984. Memoria explicativa del Mapa Geológico 1:50.000, Hoja 479 (Peñaranda de Bracamonte). Plan Magna, IGME.

López-Martínez, N. 1989. Tendencias en Paleontología. El futuro de la biogeografía del pasado. In: Nuevas Tendencias. Paleontología (Coord. E. Aguirre). C.S.I.C., Madrid, 270-296.

MacFadden, B.J. 1988. Horses, the fossil record, and evolution, a current perspective. Evolutionary Biology, 22, 131-158.

Mahboubi, M., Mebrouk, F. et Jaeger, J.J. 1997. Conséquences paléobiogéographiques tirées à partir de l'étude de quelques gisements paléogènes du Maghreb (Mammifères, Gastéropodes, Charophytes). In: Actes du Congrès BiochroM'97 (Eds. J.P. Aguilar, S. Legendre et J. Michaux). Mémoires et Travaux de l'Institut de Montpellier, École Pratique des Hautes Études, 21, 275284.

Martín, S., Jiménez, E., Fincias, B., Del Prado, J.M. y Mulas, E. 1987. Los Crocodylia del Eoceno y Oligoceno de la Cuenca del Duero. Dientes y Osteodermos. Revista Española de Paleontología, 2, 95-108.

McKenna, M.C. 1975. Fossil mammals and early Eocene North American land continuity. Annals Missouri Botanical Garden, 62, 335-353. 
Meyer, H. von. 1852. Brief an Bronn. Neues Jahrbuch Mineralogischen Geologischen Paläontologischen, Stuttgart, 831-833.

Miquel, M. 1906. Restos fósiles de Vertebrados encontrados en San Morales (Salamanca). Boletín de la Real Sociedad Española de Historia Natural, 6, 352-357.

Morales, J. y Nieto, M. 1997. El registro terciario y cuaternario de España. In: Registros fósiles e historia de la Tierra. (Dirs. E. Aguirre, J. Morales y D. Soria). Ed. Complutense, Madrid, 296-321.

Moyà, S. y Köhler, M. 1992. Primates del Paleógeno de Castilla y León: Una introducción. In: Vertebrados fósiles de Castilla y León (Coord. E. Jiménez). Museo de Salamanca, 121-125.

Noulet, M. 1851. Note sur une nouvelle espèce du genre Lophiodon. Mémoires de l'Académie de Sciences de Toulouse, 245-250.

Ortega, F.J. y Buscalioni, A.D. 1992. Cocodrilos fósiles de Castilla y León. In: Vertebrados fósiles de Castilla y León (Coord. E. Jiménez). Museo de Salamanca, 59-70.

Owen, R. 1847. On the fossil remains of Mammalia referable to the genus Palaeotherium and to two genera Paloplotherium and Dichodon, hitherto undefined from the eocene sand at Hordle, Hampshire. Quarterly Journal of Geological Society of London, 4, 17-42.

Peláez-Campomanes, P. 1992. Los Roedores del Paleógeno de Castilla y León. In: Vertebrados fósiles de Castilla y León (Coord. E. Jiménez). Museo de Salamanca, 105109.

Peláez-Campomanes, P. 1993. Micromamíferos del Paleógeno Continental Español: Sistemática, Biocronología y Paleoecología. Tesis Doctoral, Facultad de Ciencias Biológicas, Universidad Complutense de Madrid (inédita), 1-388.

Peláez-Campomanes, P. 1996. Upper Eocene rodents from the Almazán basin (Soria, Spain). Eclogae geologicae Helveticae, 89 (3), 1363-1385.

Peláez-Campomanes, P. and López-Martínez, N. 1996. Strange Eocene Rodents from Spain. Palaeovertebrata, 25 (2-4), 323-338.

Peláez-Campomanes, P., De La Peña, A. y López, N. 1989. Primeras faunas de micromamíferos del Paleógeno de la Cuenca del Duero. Stvdia Geologica Salmanticensia, volumen especial 5, 135-157.

Pictet, F.J. et Humbert, A. 1869. Mémoire sur les animaux vertébrés trouvés dans les terrains sidérolithiques du canton de Vaud et appartenant à la faune éocène. Supplément, 1-197.

Portero, J.M., Olmo, P., Ramírez, J. y Vargas, I. 1982. Síntesis del Terciario continental de la Cuenca del Duero. $1^{a}$ Reunión de la Geología de la Cuenca del Duero, Salamanca, 1979, IGME, 1, 11-40.

Prothero, D.R. and Schoch, R.M. 1989. Origin and evolution of the Perissodactyla: summary and synthesis. In: The evolution of Perissodactyls (Eds. D.R. Prothero and R.M. Schoch). Oxford University Press, 504-529.

Rat, P. 1965. La sucession stratigraphique des Mammifères dans l'Eocène du Bassin de Paris. Bulletin de la Société Geologique de France, (7), 7 (2), 248-256.
Remy, J.A. 1965. Un nouveau genre de Paleothéridé de L'Eocène supérieur de Midi de la France. Comptes Rendus de l'Académie des Sciences, Paris, 260, 43624364.

Remy, J.A. 1967. Les Palaeotheriidae (Perissodactyla) de la faune de mammifères de Fons 1 (Eocène supérieur). Palaeovertebrata, 1 (1), 1-46.

Remy, J.A. 1972. Étude du crane de Pachynolophus lavocati n.sp. (Perissodactyla, Palaeotheriidae) des Phosphorites du Quercy. Palaeovertebrata, 5, 45-78.

Remy, J.A. 1988. Le gisement du Bretou (Phosphorites du Quercy, Tarn-et-Garonne, France) et sa faune de vertébrés de l'Éocène supérieur. VIII Perissodactyles. Palaeontographica, A, 205, 155-172.

Roman, M.F. 1923. Algunos dientes de Lofiodóntidos descubiertos en España. Memorias de la Comisión de Investigaciones Paleontológicas y Prehistóricas, 33, 122.

Roman, M.F. et Royo, J. 1922. Sur l'existence des mammifères lutétiéns dans le bassin du Douro (Espagne). Comptes Rendus de l'Académie des Sciences, Paris, 175, 1221-1223.

Russell, D.E., Hartenberger, J.L., Pomerol, C., Sen, S., Schmidt-Kittler, N. and Vianey-Liaud, M. 1982. Mammals and Stratigraphy: The Paléogène of Europe. Palaeoverterbrata, Mémoire Extraordinaire, 1-77.

Sáenz, C. 1934. Nuevos yacimientos de vertebrados fósiles en la Cuenca Terciaria del Duero. Boletín de la Real Sociedad Española de Historia Natural, 34, 181-185.

Schmidt-Kittler, N. (Ed.) 1987. International Symposium on Mammalian Bioestratigraphy and Paleoecology of the European Paleogene. Münchener Geowissenschaftliche Abhandlungen, 10, 1-311.

Schmidt-Kittler, N. et Vianey-Liaud, M. 1975. Les relations entre les faunes de rongeurs d'Allemagne du Sud et de France pendant l'Oligocène. Comptes Rendus de l'Académie des Sciences, Paris, D, 281, 511-514.

Sigé, B. 1976. Insectivores primitifs de l'Éocenè supérieur et Oligocène inférieur d'Europe Occidentale. Nyctitheriides. Mémoire du Muséum National d'Histoire Naturelle, C, 34, 1-140.

Srivastava, S.P., Schouten, H., Roest, W.R., Kiltgord, K.D. et al. 1990. Iberian plate kinematics: a jumping plate boundary between Eurasia and Africa. Nature, 344, 756759.

Stehlin, H.G. und Schaub, S. 1951. Die Trigonodontie der Simplicidentaten Nager. Schweizerischen Paläontologischen Abhandlungen, 67, 1-385.

Sudre, J. 1969. Les gisements de Robiac (Eocène supérieur) et leurs faunes de Mammifères. Palaeovertebrata, 2 (3), 95-156.

Sudre, J. 1974. L'éndemisme des faunes de Mammifères du sud d'Angleterre à l'Eocène supérieur. 1ère Réunion des Sciences de la Terre, Paris, 2, 362.

Sudre, J. 1978. Les Artiodactyles de l'Eocène moyen et supérieur d'Europe occidentale (Systématique et évolution). Thèse, Université des Sciences et Techniques du Languedoc, 1-257.

Vianey-Liaud, M. 1976. Evolution des Rongeurs à 
l'Oligocène en Europe occidental. Thèse, Comptes Rendus de l'Académie des Sciences, A.0.12.290, 1-113.

Vianey-Liaud, M., Schmidt-Kittler, N et Peláez-

Campomanes, P. 1994. Pairomys et Ectropomys: la fin d'une ambiguité; mise au point sur Oltinomyinae et Remyinae (Rodentia, Mammalia). Palaeovertebrata, 23 (1-4), 119-152.
Vilanova, J. 1873. Noticias de Vertebrados hallados en Sanzoles (Zamora). Actas de la Sociedad Española de Historia Natural, 2, 41, 42, 47 y 52.

Wible, J.R. 1986. Transformation in the extracranial course of the internal carotid artery in mammalian phylogeny. Journal of Vertebrate Paleontology, 6, 313-325.

Manuscrito recibido: 16 de julio, 1998 Manuscrito aceptado: 20 de enero, 1999 